\title{
PERANCANGAN ALGORITMA EFEKTIF UNTUK MENINGKATKAN EFISIENSI ENERGI MENUJU GREEN COMPUTING
}

\author{
Oleh: Prio Handoko, M.T.I
}

\section{ABSTRAK}

Penggunaan Teknologi Informasi dan Komunikasi telah menjadi bagian dari keseharian kita. Aplikasi komputer baru, inovasi dalam perangkat lunak dan perangkat keras telah membuat pengguna dapat menggunakan teknologi dalam kesehariannya. Inovasi ini tidak dapat terjadi tanpa peran dari programmer IT.

Perubahan yang cepat ini mempunyai dampak pada lingkungan. Perangkat keras IT sebagai perangkat elektronika mengeluarkan $\mathrm{CO} 2$ dan emisi gas rumah kaca dalam pemakaiannya. Ketika algoritma program tidak efektif, perangkat elektronik perlu bekerja lebih keras yang hasilnya adalah penggunaan energi yang berlebihan. Algoritma yang lebih efektif akan menggunakan energi yang lebih rendah. Makalah ini meneliti peranan programmer IT dalam mendesain perangkat lunak melalui algoritma yang efektif.

\section{ABSTRACT}

The use of Information and communication technology has been part of our daily life. New computer applications, innovation in software and hardware have enable users to use technology in everyday life. These innovations cannot be successful without the role of IT programmers.

These rapid changes have significant impact on the environment. IT hardware as electronic devices releases $\mathrm{CO} 2$ and green house gas emission when in use. When the algorithm is not effective in running the program, the electronic devices needs to work harder which in turn resulted more power consumption. The more effective the algorithm is the less energy consumed. This paper investigates the role of IT programmers in designing software through effective algorithm.

\section{PENDAHULUAN}

Isu pemanasan global memang telah lama diku mandangkan dan banyak ilmuwan yang telah me neliti mengenai fenomena-fenomena yang dilansir sebagai dampak dari perubahan ikim tersebut, mulai dari perubahan iklim ekstrim hingga bencana- bencana alam yang terjadi di berbagai belahan du nia dan kenaikan rata-rata suhu lapisan atmosphere yang dekat dengan permukaan bumi yang dapat mengakibatkan perubahan pola iklim global[18]. Hal ini tentunya bukan terjadi dengan sendirinya, tetapi justru karena ulah manusia itu sendiri yang secara langsung ataupun tidak telah melakukan aktivitas yang dapat mengakibatkan terjadinya perubahan iklim tersebut. Aktivitas seperti, penebangan hutan secara liar dan penggunaan bahan-bahan kimia yang dapat merusak lapisanozon bumi merupakan beberapa contoh bagaimana manusia memperlakukan bumi. Selain itu sektor transportasi, sektor industri serta sektor teknologi informasi dan komunikasi (TIK) baik dari sisi perangkat lunak maupun perangkat keras turut memperparah kondisi tersebut. Oleh karena itu, dalam menanggapi hal tersebut, manusia kini dituntut un tuk dapat memberikan kontribusi agar dapat mengurangi dampak dari pemanasan global tersebut dengan melakukan 3 hal atau yang lebih dikenal sebagai 3R; reduce, refurbish dan recycle. Reduce, mengurangi penggunaan barang-barang yang sekiranya kurang ramah lingkungan, termasuk mengurangi penggunaan plastik, mempersingkat waktu mandi, mematikan listrik yang tidak terpakai. 
Refurbish, menggunakan ulang barang-barang yang masih layak pakai dan/atau memperbaruinya sehingga memiliki waktu yang lebih lama untuk digunakan.

Recycle, memilih barang-barang yang mempunyai dapat didaur ulang atau memisahkan sampah yang dapat didaur ulang dan yang tidak bisa didaur ulang. Terlepas dari 3R yang harus dilakukan untuk meminimalkan dampak pemanasan global, saya lebih memfokuskan pada dampak pemanfaatan teknologi informasi dan komunikasi terhadap kondisi ini, karena pemanfaatan TIK, baik sisi perangkat lunak (software) - seperti aplikasi yang ramah lingkungan dan perancangan algoritma efektif untuk meningkatkan komputasi dan menurunkan konsumsi energi - maupun perangkat keras (hardware) - penggunaan PC, notebook, server, power supply, sistem pendingin (cooling system), infrastuktur TI berhubungan dengan emisi gas, yang lebih dikenal dengan greenhouse gas (GHG), yang dilepas ke atmosphere bumi sehigga memberikan kontribusi terhadap terbentukya efek rumah kaca (greenhouse effect) yang pada akhirnya berdampak kepada perubahan iklim bumi. Dalam tulisan ini akan dibahas bagaimana hubungan antara pemanfaatan TIK dari sisi perangkat lunak (software) dan pemanasan global serta cara yang dapat dilakukan sebagai bagian dari kampanye hijau (green campaign) untuk meminimalkan dampak dari pemanasan global melalui pemanfaatan TIK, khususnya dalam hal perancangan algoritma yang efektif, baik sebagai bagian awal pembangunan sebuah aplikasi maupun untuk meningkatkan kinerja perangkat TIK.

\subsection{TIK DAN PEMANASAN GLOBAL}

Secara langsung dampak pemanfaatan TIK memang tidak dapat dirasakan pengaruhnya ter dap kondisi iklim bumi pada saat ini karena TIK menyumbang 2-3\% emisi gas GHG seluruh dunia[1][4][7] dan telah termasuk emisi oleh perusahaan TIK secara langsung serta konsumsi

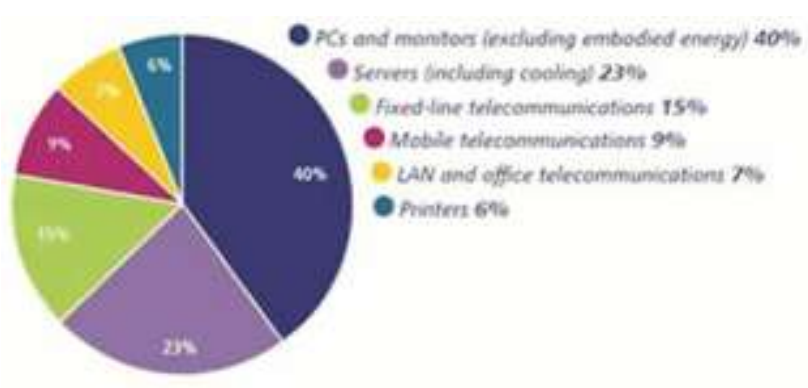

Gambar 1. Perkiraan penyebaran emisi GHG Co2 pemanfaatan TIK dunia

Sumber: http://www.greentouch.org/index. php?page=how-the-ict-industries-can-help-theworld-combat-climate-change energi peralatan TIK. Fixed-line telekomunikasi mencapai sekitar $15 \%$ dari total, sementara telekomunikasi seluler memberikan kontribusi tambahan 9\% dan LAN dan telekomunikasi kantor sekitar 7\% [4].

Pemanfaatan TIK diharapkan berkembang pesat selama dekade mendatang, terutama di negaranegara berkembang. Jika tidak ada yang dilakukan, kontribusi TIK terhadap emisi gas rumah kaca global diproyeksikan akan berlipat ganda menjadi sekitar 4\% pada tahun 2020[4]. Emisi gas yang dihasilkan dari pemanfaatan TIK ini merupakan akibat adanya pelepasan gas $\mathrm{Co} 2 \mathrm{ke}$ udara ketika perangkat TIK digunakan. Jumlah rata-rata energi yang dikonsumsi oleh PC - sebagai salah satu pemanfaaan TIK - dalam 1 tahun sesuai dengan emisi 1 ton Co 2 (MtCo2e - Million metric tons of carbon dioxide equivalent) [9]. Selain itu, 70\% dari tempat pembuangan sampah timbal, kadmium dan merkuri berasal dari industri TI[1]. Ketika perangkat TIK digunakan, perangkat membutuhkan daya dan daya ini mengakibatkan komponen-komponen yang berada di dalam perangkat menjadi panas dan panas inilah yang kemudian akan melepaskan gas $\mathrm{Co} 2$ ke udara. Semakin banyak perangkat TIK yang digunakan, maka akan semakin banyak pula emisi gas GHG yang terlepas ke udara dan semakin banyak emisi gas GHG yang terlepas ke udara, maka akan semakin meningkatkan dampak efek rumah kaca terhadap bumi. Gas Co2 memang bukan satu-satunya yang menyebabkan terjadinya efek rumah kaca, gas metana $(\mathrm{CH} 4)$ dan nitro oksida (N2o) merupakan unsur kimia yang juga turut terlepas ke udara yang juga turut andil dalam pembentukan efek rumah kaca.

\subsection{PEMBANGUNAN BERKELANJUTAN}

Menurut sebuah komisi dunia yang menangani permasalahan pembangunan dan lingkungan dunia yaitu United Nationals Global Commission on the Environment and Development (1987), yang dimaksud dengan sustainable development atau pembangunan yang berkelanjutan adalah pembangunan yang sesuai dengan kebutuhan masa depan tanpa mengganggu kemampuan generasi yang akan datang untuk memenuhi kebutuhannya. Berdasarkan definisi mengenai pembangunan yang berkelanjutan tersebut, maka sebuah pembangunan yang dilakukan, dalam bentuk apapun dan menyangkut sektor atau bidang apapun sudah seharusnya juga memikirkan kelangsungan hidup generasi yang akan datang, bukan hanya generasi dari anak cucu kita, tetapi juga kelangsungan hidup ekosistem bumi. Hal ini merupakan tanggung- 


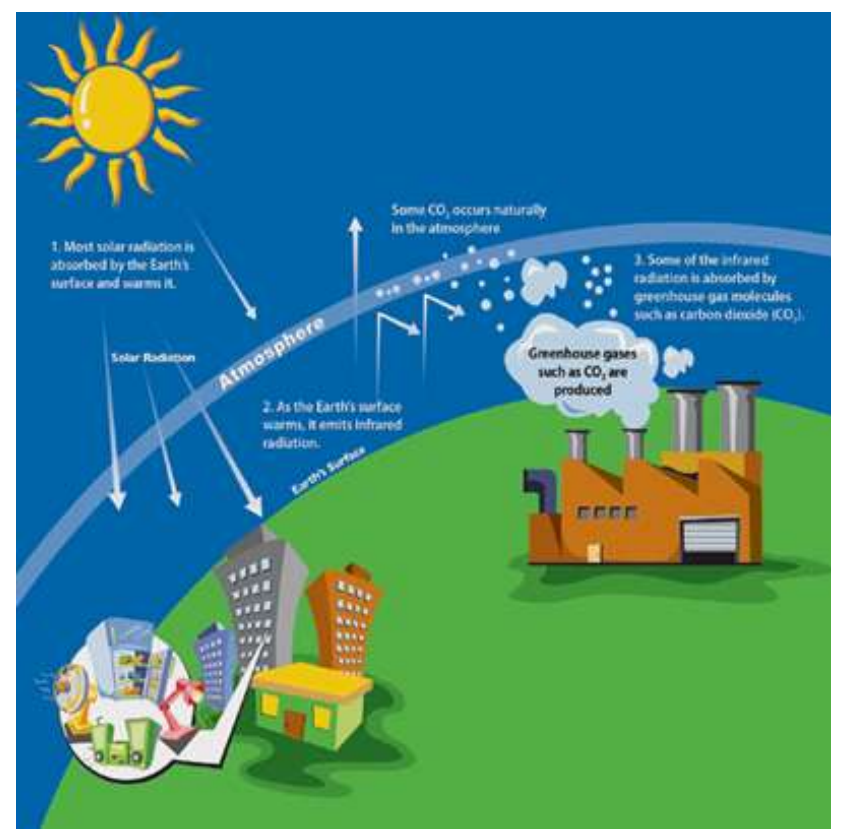

Gambar 2. Ilustrasi efek rumah kaca Sumber: http://infactcollaborative.com/environment/interesting-facts-about-global-warming.html

jawab semua pihak untuk turut serta dalam men ciptakan masa depan yang lebih baik bagi geneasi berikutnya. Pemerintah, individu dan para pelaku industri, baik yang bergerak di sektor transportasi, manufaktur maupun teknologi informasi dan komunikasi harus bersama-sama untuk membuat kondisi bumi yang lebih baik.

Pemerintah menetapkan regulasi-regulasi dan sanksi-sanksi yang berkenaan dengan penggunaan material-material berbahaya bagi sektor industri manufaktur, menetapkan regulasi mengenai batas ambang emisi yang diperbolehkan bagi kendaraan-kendaraan bermotor ataupun mesin-mesin industri dan regulasi mengenai penanganan limbah industri.

Para pelaku industri, melakukan manajemen pembuangan limbah yang baik agar tidak merusak lingkungan, menggunakan material-material yang ramah lingkungan, penggunaan bahanbahan kimia yang berbahaya dan mensubstitusinya dengan bahan-bahan yang lebih ramah lingkungan. Mengakomodasi kebutuhan dan kepentingan menciptakan kondisi lingkungan yang lebih baik, para pelaku TI diharapkan dapat mendukung pembangunan yang berkelanjutan ini dari dua sisi, perangkat lunak (software) dan perangkat keras ( hardware).

\subsection{TIK DAN PEMBANGUNAN BERKELAN- JUTAN}

Seperti yang kita ketahui bersama, bahwa pemanfaatan TIK - bagaimanapun - mempengaruhi lingkungan kita dalam berbagai cara. Setiap tahapan siklus hidup perangkat TIK, dimulai dari produksi, penggunaan hingga tahap pembuangan limbah perangkat TIK, menyebabkan permasalahan lingkungan. Manufaktur komputer dan berbagai komponen elektronik mereka dan non-elektronik mengkonsumsi listrik, bahan baku, bahan kimia dan air, dan menghasilkan limbah berbahaya.

Semua ini secara langsung atau tidak langsung meningkatkan emisi karbon dioksida dan dampak lingkungan. Jumlah konsumsi energi listrik oleh server, komputer, monitor, data peralatan komunikasi dan pusat data sistem pendingin terus meningkat. Hasil peningkatan ini dalam emisi gas rumah kaca yang lebih besar, seperti listrik sebagian besar dihasilkan oleh pembakaran bahan bakar fosil seperti batubara, minyak dan gas.

Misalnya, setiap PC yang digunakan menghasil-

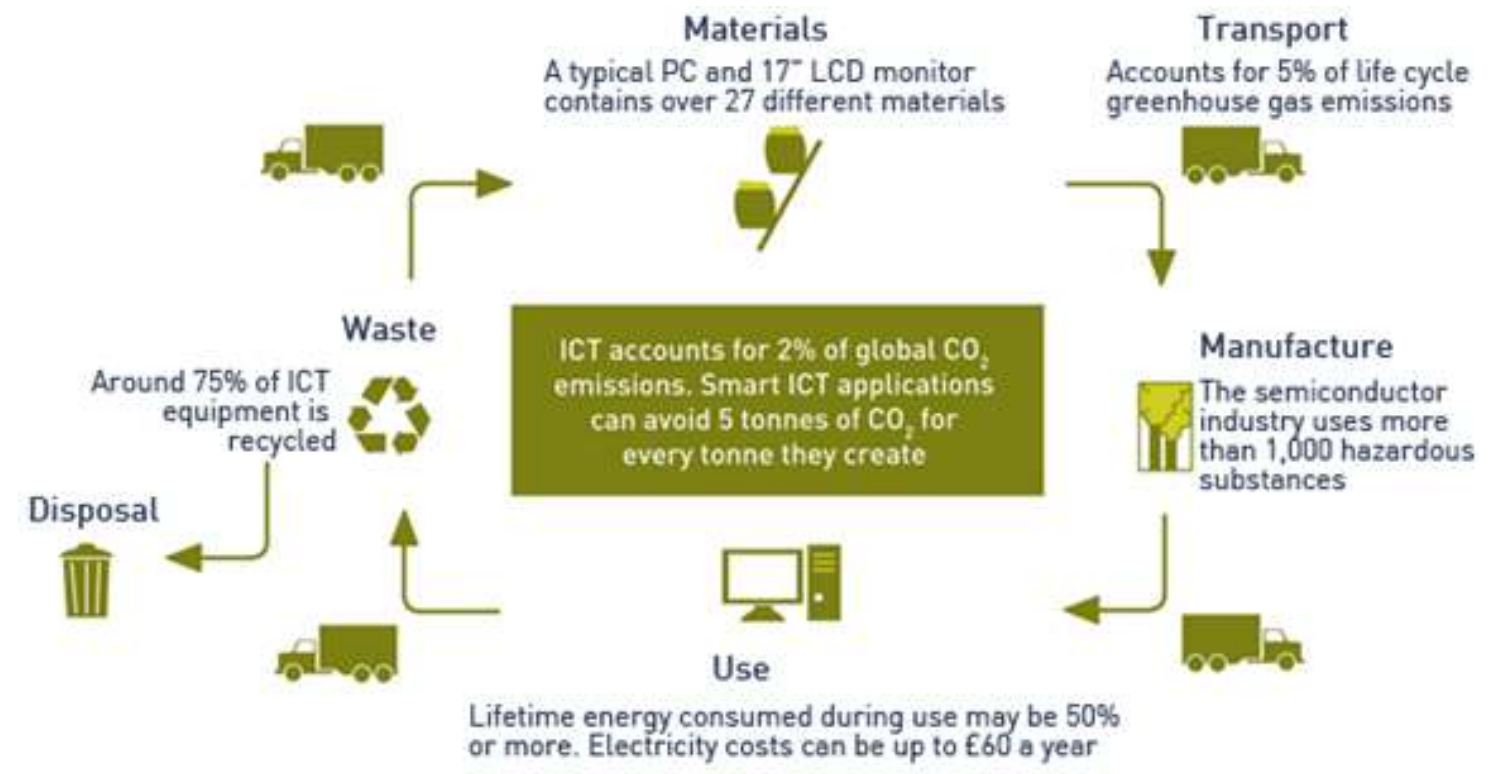

Gambar 3. Siklus hidup TIK

Sumber: http://www.jisc.ac.uk/whatwedo/topics/greenict/jischelp.aspx 
kan sekitar satu ton karbon dioksida (CO2) setiap tahun dan tidak dipungkiri bahwa material komponen komputer mengandung bahan beracun.

Semakin tinggi jumlah pengguna yang membuang perangkat lama, seperti monitor, keyboard, mouse, printer dan peralatan elektronik lainnya 2 hingga 3 tahun setelah pembelian di tempat pembuangan sampah, hal ini bukan hanya akan mencemari air tetapi secara luas akan mencemari bumi.

Peningkatan jumlah komputer dan penggunaannya, bersama dengan penggantian sering mereka, membuat dampak lingkungan TI menjadi perhatian utama. Akibatnya, ada tekanan yang meningkat pada industri TI, bisnis dan individu untuk membuat TI ramah lingkungan sepanjang siklus hidupnya, dari lahir sampai mati untuk kelahiran kembali. Disinggung pada bagian awal dari tulisan ini, bahwa para pelaku TI dapat mendukung pembangunan yang berkelanjutan ini dari dua sisi; perangkat lunak dan perangkat keras.

\subsubsection{PEMBANGUNAN BERKELANJUTAN DARI SISI PERANGKAT KERAS}

Sebagai rangkaian dari upaya melakukan kampanye hijau, banyak hal yang dapat dilakukan oleh para pelaku TI dari sisi perangkat keras, anatar lain:

1. Khususnya para produsen perangkat-perangkat TIK, dituntut untuk dapat menciptakan sebuah perangkat yang menggunakan material ramah lingkungan dan mengelola dengan baik limbah TIK sebagai sisa hasil produksi (Murugesan, 2008).

2. Menggunakan teknik hardware virtualization, yaitu Ini menyembunyikan karakteristik fisik dari platform komputasi dari pengguna[3][11], sehingga perangkat pengguna dapat saling berkomunikasi walaupun memiliki perbedaan sistem operasi. Hal ini akan mengurangi kegiatan penyediaan perangkat keras untuk menga- komodir kebutuhan komunikasi antar perangkat dengan sistem operasi yang berbeda-beda.

\subsubsection{PEMBANGUNAN BERKELANJUTAN DARI SISI PERANGKAT LUNAK}

Pelaku TI, khususnya programmer dan perancang aplikasi/utilitas dapat melakukan beberapa hal untuk mendukung kampanye hijau ini dengan cara :

1. Melakukan implementasi TIK pada proses bisnis dari bentuk konvensional ke bentuk terkomputerisasi untuk mengurangi emisi gas GHG di udara.

2. Membangun aplikasi yang ramah lingkungan dalam artian proses komputasinya membutuh kan daya yang rendah sehingga dapat melakukan penghematan energi[7][8].

3. Melakukan perancangan algoritma efektif :

a. Sisi aplikasi, sebagai dasar atau panduan pembuatan sebuah program, efektif mengacu kepada pencapaian target hasil pengolahan program yang ingin dicapai menggunakan sejumlah komputasi yang rendah dengan tetap mempertahankan performa kinerja yang baik, sehingga dapat mengurangi beban sistem yang secara langsung akan berimbas pada efisiensi daya komputasi.

b. Sisi perangkat, dilakukan untuk meningkatkan performa perangkat untk menurunkan pemakaian energi.

\section{TINJAUAN TEORITIS}

\subsection{GREEN IT}

Green IT atau green computing atau ICT sustainability, mengacu pada teknologi sistem informasi yang ramah lingkungan[7][8]. Ramah lingkungan dalam hal ini memiliki pengertian bahwa sebuah komputasi yang dilakukan harus dapat melakukan efisiensi terhadap penggunaan sumber energi, baik waktu komputasi maupun konsumsi daya yang di-

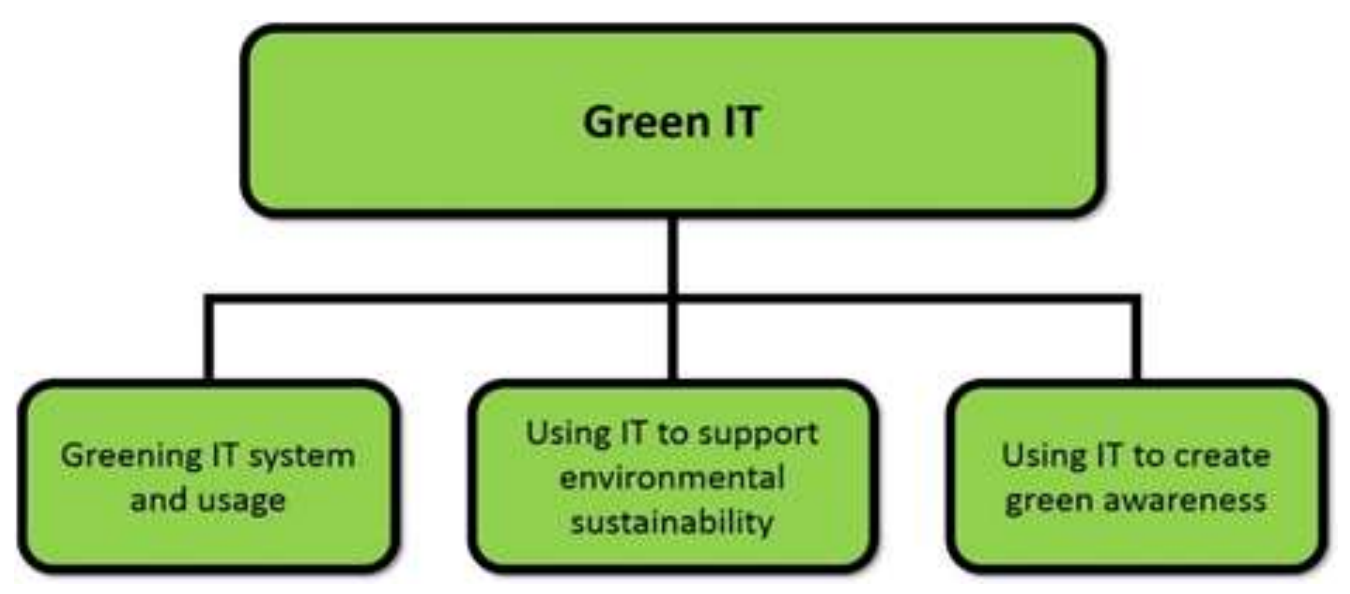


gunakan untuk menyelesaikan suatu kegiatan komputasi. Green IT mengacu kepada 3 hal yang mendasari peningkatan kelestarian lingkungan melalui pendekatan TIK[7][8]. Greening IT system and usage, melakukan perancangan, pembuatan, penggunaan dan pembuangan limbah perangkat keras TIK, perangkat lunak dan sistem komunikasi yang efektf dan efisien yang memiliki dampak minimal terhadap lingkungan.

"Using IT to support environmental sustainability", penggunaan TI dan sistem informasi untuk memberdayakan inisiatif lingkungan. "Using IT to create green awareness", memanfaatkan TIK untuk membantu menciptakan kesadaran para pemangku kepentingan dan mempromosikan green campaign. Salah satu contoh bagaimana TIK dimanfaatkan untuk dapat mengurangi dampak emisi gas GHG (gambar 4) melalui implementasi sistem pembacaan meter otomatis dengan pemantauan terpusat yang terkoneksi menggunakan jaringan yang dilakukan oleh pemerintah Jepang[17]. Sebelum dilakukannya otomatisasi manfaatkan TIK, pembacaan meter penggunaan air/gas/listrik dilakukan dari rumah ke rumah secara manual, kemudian data hasil pembacaan dari rumah ke rumah terebut diberikan ke pusat untuk disimpan ke dalam basis data dan terakhir, untuk memastikan bahwa tidak terjadi kesalahan pembacaan dan mungkin kerusakan yang terjadi pada alat pengukur pemakaian dilakukan pemeliharaan alat dengan cara mendatangi kembali dari rumah ke rumah.

Pembacaan meter yang dilakukan secara manual mengharuskan petugas mendatangi satu rumah ke rumah yang lainnya menggunakan kendaraan bermotor dalam jumlah banyak karena lokasi pembacaan meter pun jumlahnya cukup banyak.

Banyakanya kendaraan bermotor yang digunakan untuk mendatangi lokasi-lokasi pembacaan tentunya akan meningkatkan kadar CO2 di udara sehingga meningkatkan kadar polusi udara.

Berbeda dengan ketika TIK sudah diimplementasikan dalam proses pembacaan meter ini, petugas tidak lagi mendatangi satu rumah ke rumah lainnya, karena tugas pembacaan meter sudah digantikan oleh sebuah alat meter yang terkoneksi langsung ke pusat data melalui jaringan komputer.

Menggantikan cara manual dengan pemanfaatan TIK tentunya secara signifikan akan mengurangi emisi gas GHG CO2.

\subsection{ALGORITMA}

Algoritma merupakan urutan langkah-langkah logis yang tersusun secara sistematis dan logis yangdigunakan sebagai rujukan memecahkan suatumasalah[6]. Kata "algoritma" itu sendiri diambildari nama belakang seorang matematikawan, astronom dan geografer berkebangsaan arab selama "Al-Khawarizmi" dengan nama lengkap Abu Ja'far Muhammad ibn Musa al-Khwarizmi.

Perlu digarisbawahi, bahwa penekanan algoritma adalah pada urutan langkah-langkah logis yang ter-susun secara sistematis, artinya algoritma harusmengikuti suatu urutan tertentu dan tidak boleh melompat-lompat. Semakin tidak beraturannya urutan langkah-langkah penyelesaian masalah dalam suatu algoritma akan berdampak pada meningkatnya beban dan konsumsi daya komputasi sistem komputer dan hal ini merupakan tuntutan bagi semua pemrogram aplikasi.

Aplikasi merupakan sebuah paket lengkap kumpulan program yang tersusun secara sistematis dan logis yang kemudian akan dieksekusi oleh pemroses, agar pemroses memahami yang diinginkan oleh pemrogram, maka sebuah algoritma kemudian ditulis dalama notasi bahasa pemrograman.

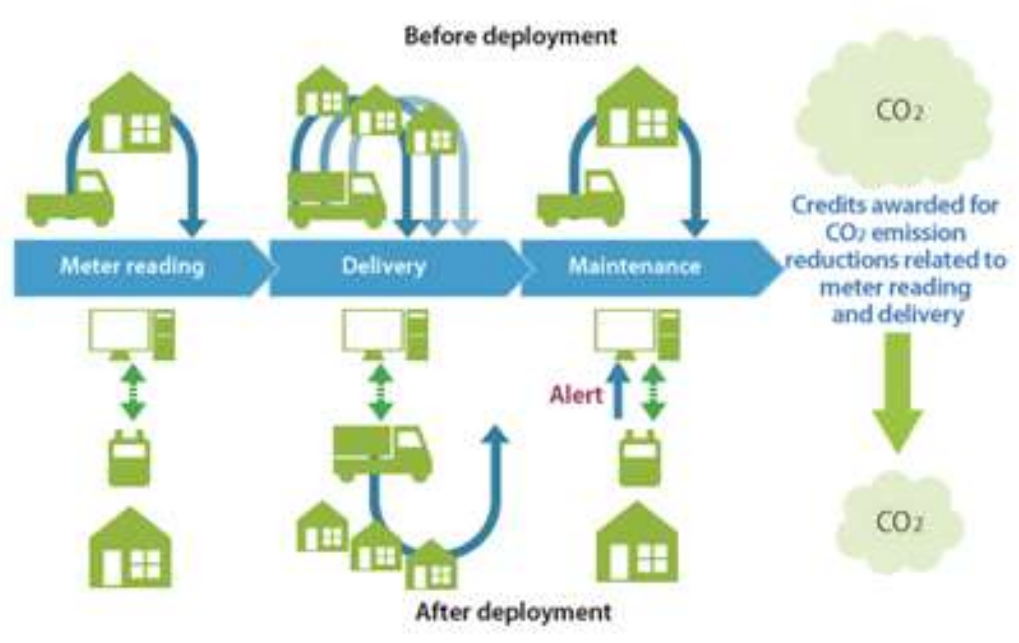

Gambar 5. Solusi hijau berbasis TIK untuk mengurangi emisi GHG gas Co2 Sumber: http://www.ntt.co.jp/kankyo/e/protect/greenbyict/group.html 


\subsubsection{PENYAJIAN ALGORITMA}

Secara umum, penyajian algoritma yang umum digunakan terdiri dari 2 teknik, flowchart dan pseudocode.

\subsubsection{FLOWCHART}

Flowchart adalah urutan logika sebuah kegiatan yang merupakan hasil analisa dan digambarkan dengan simbol-simbol yang berisi keterangan[6]. Simbolsimbol flowchart secara garis besar terbagi menjadi 3 jenis:

1. Simbol flow direction, simbol ini menandakan arah alur flowchart yang terdiri dari simbol arus/flow, connector dan offline-connector.

2. Simbol processing, simbol yang menyatakan kegiatan pengolahan yang dilakukan oleh pemroses, baik pengolahan aritmatika maupun logika, terdiri dari simbol process dan decision.

3. Simbol I/O, simbol yang menandakan kondisi masukan data dan keluaran hasil pengolahan yang digambarkan dengan simbol input-output.

\subsubsection{2. pSeudo-code}

Pseudo-code merupakan penjelasan rinci alur logika yang lebih mendekati penulisan program komputer atau algoritma yang harus dilakukan tetapi belum dapat dieksekusi oleh komputer. Psendo-code terkadang digunakan sebagai sebuah tuntunan langkah-langkah rinci dalam proses pengembangan

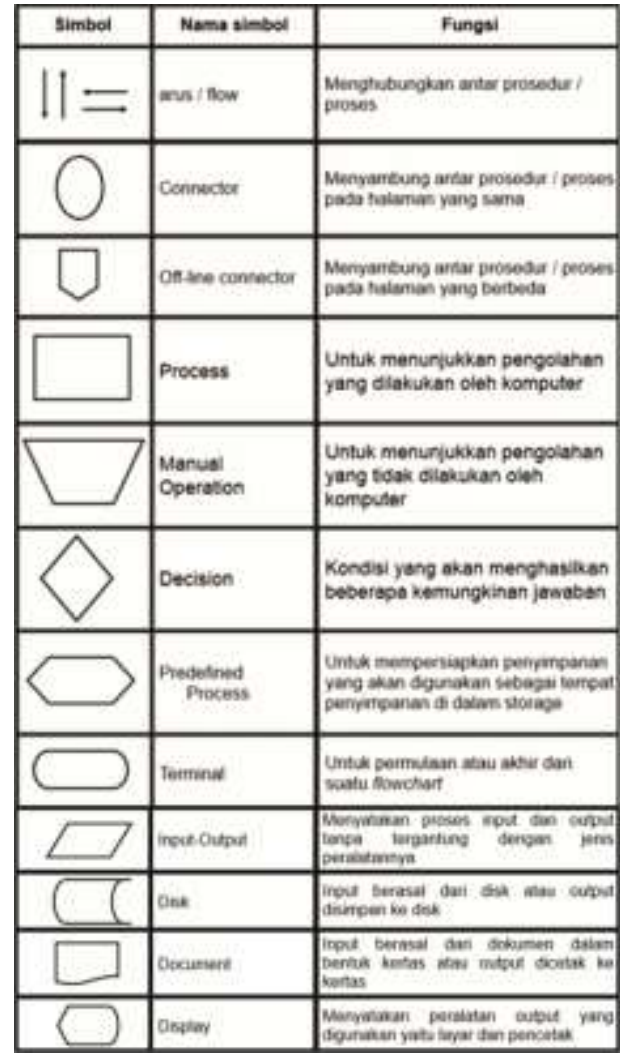

Tabel 1. Simbol-simbol flowchart program. Pseudo-code memungkinkan; (1) seorang pemrogram untuk mengarahkan program sesuai dengan rancangan yang telah dibuat sebelumnya dan (2) memberikan programmer sebuah landasan rinci untuk langkah berikutnya dalam menuliskan kode dalam bahasa pemrograman tertentu.

\section{ALGORITMA EFEKTIF DAN EFISIENSI EN- ERGI}

\subsection{PENTINGNYA ALGORITMA EFEKTIF}

Merancang sebuah algoritma yang efektif bagi seorang pemrogram adalah penting artinya karena salah satu ciri dari algoritma yang harus dipahami oleh setiap pemrogram adalah bahwa, algoritma haruslah dirancang seefektif dan seefisien mungkin, setiap alur pemikiran logis dibuat sedemikian rupa sehingga dapat diselesaikan dalam kurun waktu yang masuk akal yang pada akhirnya akan mengarah kepada pengurangan waktu komputasi yang berdampak pada berkurangnya konsumsi daya. Implikasi dari perancangan algoritma yang efektif adalah berkurangnya baris perintah yang dituliskan dalam sebuah program, berkurangnya penulisan baris perintah akan mengurangi beban pengolahan pemroses untuk mengeksekusi setiap baris perintah tersebut, dengan berkurangnya beban penglohan tentunya secara langsung akan mengurangi konsumsi daya. Majalah sains, New Scientist[12] dan Scientific American[13] dalam sebuah artikelnya menuliskan bahwa pada masa sekarang

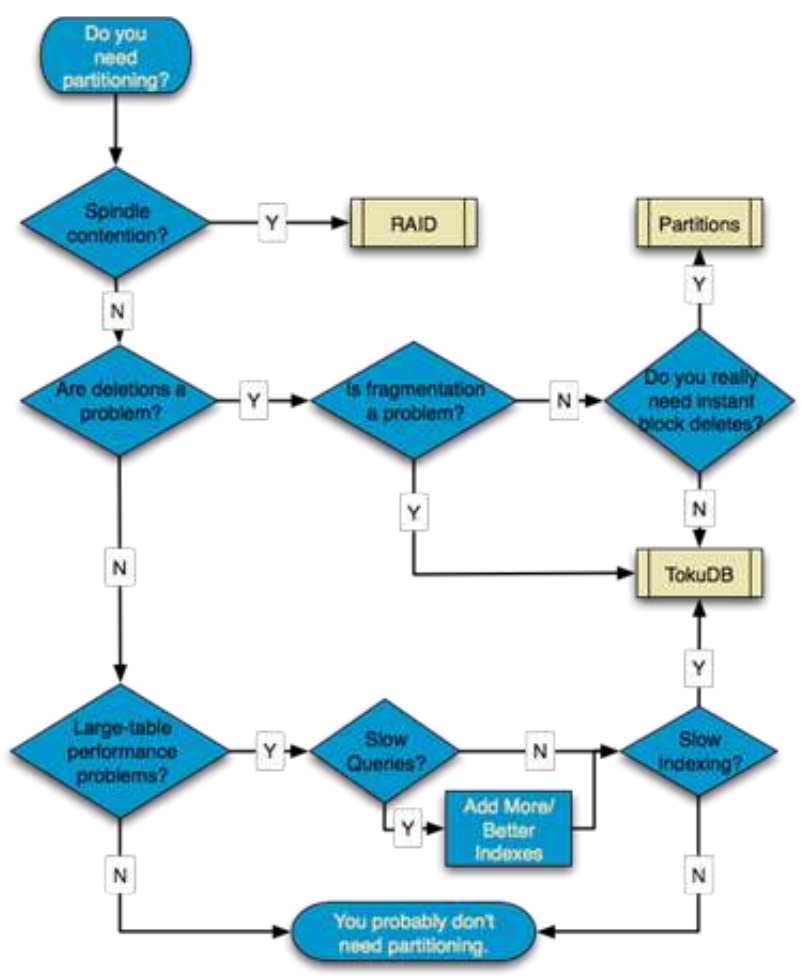

Gambar 6. Contoh penggambaran flowchart Sumber: http://www.tokutek.com/2011/03/mysql-parti- tioninga-flow-chart/ 


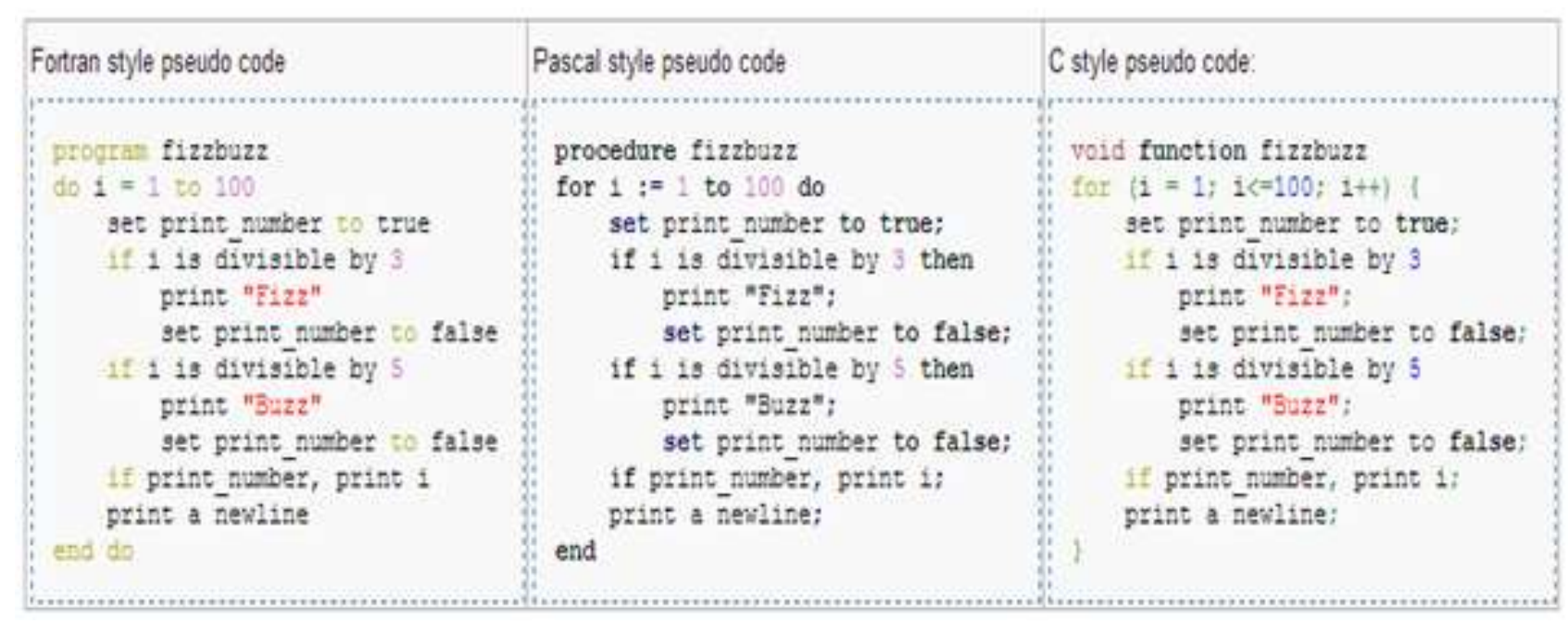

Gambar 7. Contoh penulisan pseudo-code Sumber: http://en.wikipedia.org/wiki/Pseudocode

ini jaringan telekomunikasi dimungkinkan hanya mengkonsumsi 1/10000 daya jika menggunakan teknik penulisan progam (coding) yang tepat.

Berbicara mengenai teknik penulisan program, maka hal ini akan berkenaan dengan perancangan algoritma sebagai panduan penulisan program, artinya jika sebuah algoritma dapat dituliskan dengan efektif, maka energi yang dikonsumsi untuk pengolahan akan dapat ditekan lebih rendah lagi.

\subsection{PERANCANGAN DAN IMPLEMENTASI ALGORITMA EFEKTIF}

Performa infrastruktur TIK yang diimplementasikan untuk suatu kebutuhan tentunya tidak terlepas dari perancangan algoritma aplikasi/utilitas sebagai dasar instruksi yang harus dilakukan oleh perangkat TIK. Semakin efektif sebuah algoritma dirancang dan kemudian diimplementasikan, maka komputasi yang dilakukan di dalam perangkat TIK akan semakin efisien, baik dari sisi waktu maupun jumlah data yang diproses.

Perancangan dan implementasi algoritma efektif dalam pembangunan aplikasi/utilitas untuk perangkat TI sudah banyak dilakukan, beberapa artikel dan tulisan ilmiah telah banyaka dihasilkan untuk memperlihatkan bagaiamana sebuah perancangan dan pemilihan algoritma yang efektif dapat menurunkan penggunaan energi perangkat TIK.

\subsubsection{PHYSICAL LAYER DRIVEN PROTO- COL AND ALGORITHM DESIGN FOR enerGy-efficient Wireless Sen- Sor netWorkS[10]}

Makalah ilmiah ini menjelaskan dua buah tehnik penempatan posisi sensor-sensor terhadap sensor induk. Perangkat sensor yang digunakan adalah microsensor jaringan nirkabel yang digunakan un- tuk kebutuhan, penginderaan-lokasi, penginderaan lingkungan, pemantauan medis dan penggunaan lainnya yang memiliki kesamaan kebutuhan. Permasalah yang muncul dari penggunaan perangkat microsensor jaringan nirkabel ini adalah pengunaan perangkat ini harus dapat dipergunakan dalam jangka waktu yang panjang, penginderaan yang kuat (seperti pengintaian militer), dimana tantangannya adalah untuk merancang sistem jaringan sensor yang memiliki daya tahan lama dan hal ini akan sangat sulit dilakukan mengingat perangkat memilki keterbatasan dalam hal kebutuhan energi perangkat. Dalam rangka untuk mengatasi permasalah kebutuhan energi perangkat yang terabatas tersebut, penulis menawarkan sebuah rancangan protokol dan algoritma agar jaringan microsensor nirkabel ini dapat memiliki energi tahan yang sangat lama.

Perangkat sensor nantinya akan diletakkan menyebar dalam kelompok-kelompok sensor dan masing-masing kelompok ini akan mememiliki sebuah sensor induk (cluster-head) dan setiap sensor, baik sensor anak (child sensor) maupun cluster-head akan dimuatkan sebuah program yang mengontrol perangkat, yaitu FFT (Fast-Fourier Transform), mer-

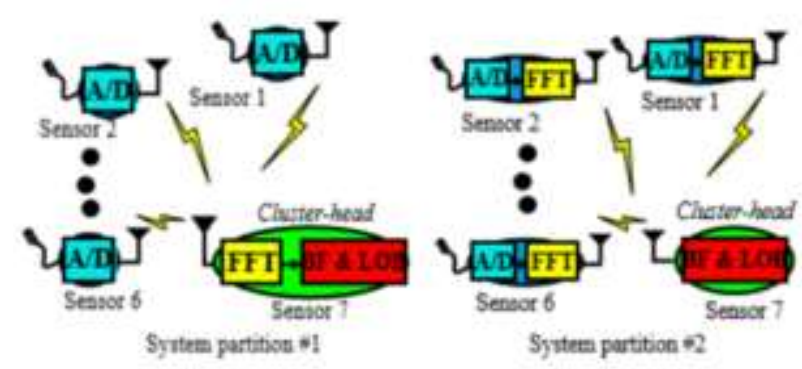

Gambar 8.

(a) Direct technique; (b) Distributed technique 
upakan bagian dari pengontrol perangkat yang mengubah sinyal transmisi hasil penginderaan (beamforming) [14] dan mengubah data yang hasil penginderaan tersebut ke dalam bentuk frekuensi dan LOB (Line of Bearing), merupakan garis pancaran/penginderaa sensor. Algoritma penempatan lokasi cluster-head terhadap sensor child dapat diimplementasikan dalam dua teknik:

1. Direct Technique, teknik yang mengirimkan data ke cluster-head dimana FFT dan beamforming dimuatkan di dalam cluster-head.

2. Distributed Technique, setiap sensor dapat mengubah data lokal sebelum mengirim data ke clusterhead, hal ini dikarenakan FFT ditempatkan di sensor child sedangkan beamforming ditempatkan di cluster-head.

Setelah kedua teknik ini dibandingkan berdasarkan penggunaan energi dari setiap perangkat yang digunakan dan implementasi Dynamic Voltage Scaling (DVS), maka dihasilkan bahwa teknik distributed menggunakan energi yang lebih rendah jika dibandingkan dengan teknik direct.

\subsubsection{CHOOSING THE "BEST" SORTING AL- GORITHM FOR OPTIMAL ENERGY}

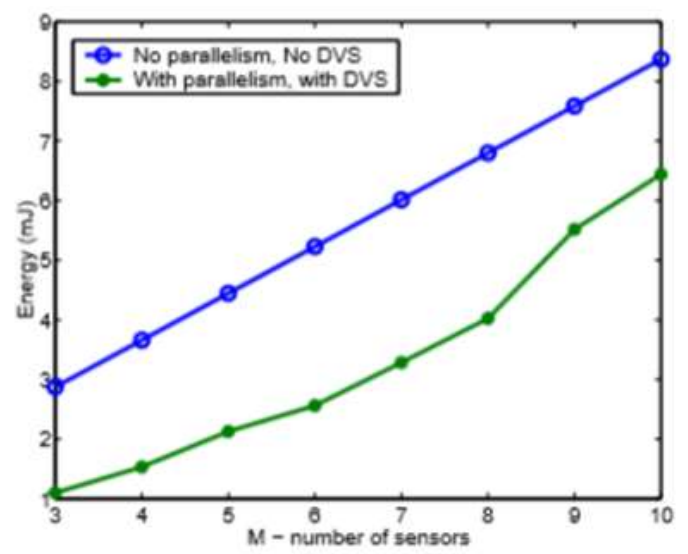

Gambar 9.

Perbandingan penggunaan energi teknik direct dan distributed

\section{conSuMption[2]}

Perhatian utama pada penelitian berikut ini adalah mengurangi konsumsi daya baterai dari sistem perangkat bergerak (mobile) untuk memperpanjang waktu operasi karena perangkat sangat bergantung pada konsumsi daya dari komponen yang digunakan. Makalah ini membahas mengenai kemungkinan strategi yang digunakan oleh sistem perangkat bergerak yang secara efektif untuk mengurangi konsumsi daya. Fokus dari makalah ini didasarkan pada studi kasus yang menggunakan komponen manajemen energi yang secara dinamis dapat memilih algoritma pengurutan (sorting) terbaik dalam komunikasi antar banyak perangkat bergerak dan 2 buah algoritma pengurutan yang dipilih dari 8 algortima pengurutan yang ada, yaitu algoritma pengurutan insertion sort dan quick sort.

\subsubsection{INSERTION SORT}

Sebuah teknik sederhana pengurutan nilai referensi yang memindai nilai satu per satu, mulai dari awal secara berulang-ulang dan memasukkan setiap data ke dalam tempatnya yang benar[15].

\subsubsection{QUICK SORT}

Sebuah teknik pengurutan nilai sequential dengan cara terus membagi referensi menjadi dua bagian dan memindahkan nilai yang lebih rendah ke satu sisi dan nilai yang lebih tinggi ke yang lain[16].

Makalah ini merupakan sebuah pembuktian mengenai perlu atau tidaknya optimalisasi algoritma pemilahan dilakukan terhadap algoritma insertionsort. Setelah dilakukan pegujian, ternyata hasilnya cukup mengagetkan, karena ternyata masa pakai baterai algoritma insertionsort masih lebih baik jika dibandingkan dengan ketika algoritma ini dioptimalisasikan.

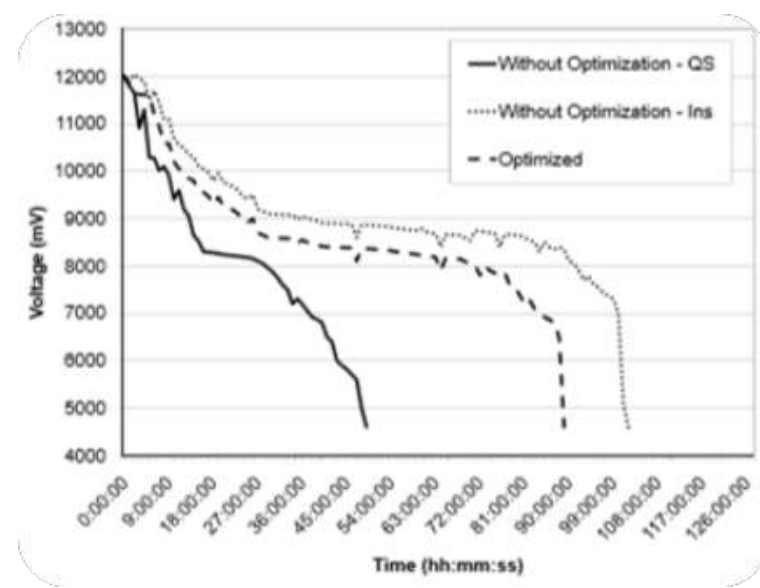

Gambar 10.

Perbandingan masa pakai baterai perangkat bergerak antara algoritma pemilahan quicksort dan insertionsort yang tidak diptimalisasikan dan algoritma insertionsort yang dioptimalisasikan.

\subsubsection{ENERGY EFICIENT CLUSTERING AL- GORITHM FOR MAXIMIZING LIFETIME OF WireleSS SenSor netWorKS[5]}

Makalah berikut menggunakan algoritma pengelompokkan (clustering algorithm) untuk melakukan efisensi energi perangkat sensor jaringan nirkabel yang bertindak sebagai simpul (node) dalam jaringan nirkabel. Seperti kita ketahui bersama bahwa perangkat sensor dalam jaringan ini merupakan perangkat keras yang sangat bergantung kepada ketersediaan energi, sehingga memaksimalkan 
masa hidup seluruh jaringan merupakan pertimbangan utama dalam perancangan jaringan nirkabel ini. Oleh karena itu, dibutuhkan sebuah algoritma efisien untuk mengelompokkan sensor-sensor ini menggunakan parameter optimum dan dirancang untuk mengurangi konsumsi daya serta dapat memperpanjang masa hidup sistem. Optimalisasi jarak satu-lompatan ( $h o p$ ) dan mengatur posisi

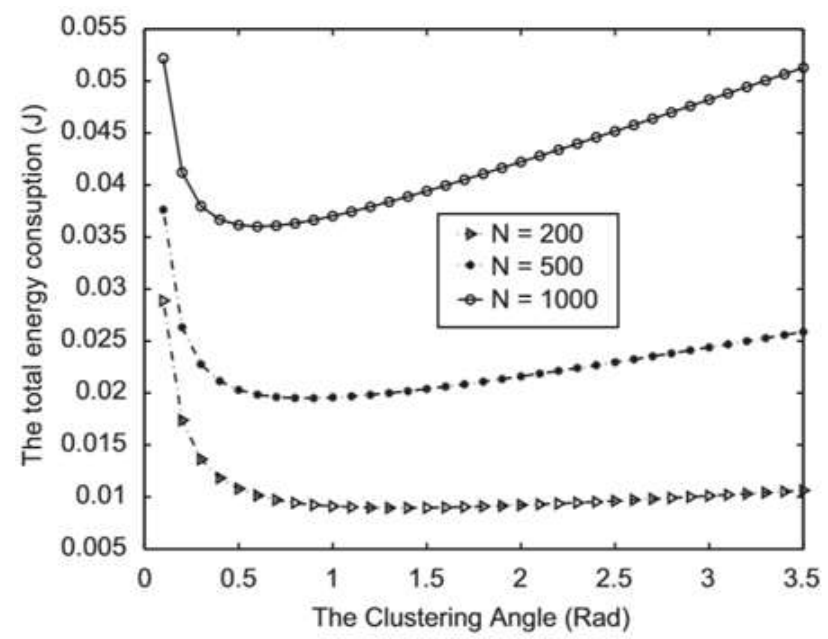

Gambar 11. Perbandingan total konsumsi daya pengelompokkan sensor dengan jumlah simpul yang berbeda-beda

kelompok sensor-sensor ini dirumuskan dengan meminimalkan konsumsi daya antarkelompok di luar dan antarkelompok di dalam sistem jaringan nirkabel.

Selain itu, mekanisme kerja pada setiap cluster-head - yang bertindak sebagai pusat kontrol lokal - tidak akan digantikan oleh cluster-head yang baru hingga mencapai nilai suatu nilai optimum dan waktu optimal mekanisme kerja pada setiap cluster-head dapat dipertahankan melalui optimalisasi jarak satu-lompatan dan mengatur posisi kelompok sensor-sensor. Mekanisme ini akan mengurangi frekuensi memperbarui cluster-head sehingga konsumsi daya untuk membangun cluster-head baru dapat dikurangi.

Gambar di atas memperlihatkan hubungan antara total konsumsi daya dan pengelompokkan sensorsensor berdasarkan jumlah sensor yang berbedabeda. Kesimpulan yang dapat diambil dari pengujian algoritma pengelompokkan ini adalah:

1. semakin banyak jumlah simpul dalam sebuah kelompok sensor akan meningkatkan total konsumsi daya, hal ini diakibatkan dari seringnya perbaruan cluster-head,

2. semakin sedikitnya jumlah simpul ditambah dengan implementasi algoritma pengelompokkan dan mengatur posisi kelompok sensor dengan tepat mengurangi perbaruan cluster-head sehingga menurunkan total konsumsi daya,

3. dengan mengoptimalkan jarak satu-lompatan dan mengatur posisi kelompok sensor-sensor yang tepat, maka semua simpul akan terbagi menjadi kelompok-kelompok statis dengan ukuran yang berbeda yang dapat mempertahankan konektivitas dan mengurangi konsumsi energi untuk melakukan komunikasi antar kelompok, dan

4. pemilihan algoritma pengelompokkan (clustering) mengakibatkan total konsumsi daya untuk komunikasi antar kelompok di luar dan di dalam jaringan nirkabel akan berkurang.

Beberapa contoh penelitian diatas telah memperlihatkan bagaimana perancangan, pemilihan dan implementasi sebuah algoritma yang tepat dan efektif dapat mengurangi konsumsi daya. Jika hal ini terus-menerus dikembangkan dan semua orang melakukan hal yang sama, maka lambat-laun konsentrasi emisi gas GHG di udara akan dapat ditekan serendah mungkin dan diharapkan kondisi bumi semakin hari semakin membaik.

\section{KESIMPULAN}

Kesimpulan yang dapat diambil dari bahasan mengenai perancangan algoritma efektif untuk meningkatkan efisiensi energi ini adalah:

1. porsi emisi GHG perangkat TIK di udara sebenarnya masih lebih kecil jika dibandingkan porsi emisi GHG perangkat non-TIK, hanya sekitar $2-3 \%$ tiap tahunnya, hanya saja jika tidak diatasi mulai saat ini, maka tahun 2020 nanti kondisi ini akan meningkat 4 kali lipat,

2. perancangan algoritma efektif tidak hanya dilakukan dengan cara menuangkannya dalam bentuk flowchart ataupun pseudo-code, tetapi dapat dituangkan dalam bentuk rancangan optimalisasi pola letak perangkat TIK dalam sebuah jaringan komputer untulk menurunkan konsumsi daya sistem secara keseluruhan,

3. para pelaku TI, khususnya yang juga berprofesi sebagai peneliti, telah banyak melakukan penelitian mencari solusi melakukan efisiensi energi dari penggunaan perangkat TIK sebgai bentuk kampanye hijau, dan

4. menciptakan sustainable development merupakan tanggungjawab semua pihak, bukan hanya para pelaku TI saja (walaupun prosi emisi GHG cukup rendah), tetapi pemerintah dan setiap individu dari kita pun memiliki andil untuk bersama-sama mengatasi hal ini.

Harapan saya sebagai pembahasan lanjutan mengenai perancangan algoritma efektif ini, bahwa adanya pembahasan mengenai perancangan algoritma efektif dan non-efektif berdasarkan sebuah studi kasus yang kemudian hasilnya dibandingkan dengan cara melakukan pengukuran terhadap 
efektifitas algoritna yang dibuat dan mengkaitkannya dengan efisiensi energi.

\section{DAFTAR PUSTAKA}

1. Brown, E.G., Lee C., 2007, “Topic Overview: Green IT", Forrester Research Report.

2. Bunse, C., Höpfner, H., Roychoudhury, S., Mansour, E., 2009, "Choosing the "Best" Sorting Algorithm for Optimal Energy Consumption", Hal. 199-206, ICSOFT.

3. IBM, "Virtualization in Education", Oktober 2007, IBM Global Education White Paper.

4. Kumar, R., Lars, M., 2007, "Conceptualizing "Green IT" and Data Centre Power and Cooling Issues", Gardner Research Paper No. G00150322.

5. Min, X., Wei-ren, S., Chang-jiang, J., Ying, Z., 2008, "Energy Efficient Clustering Algorithm for Maximizing Lifetime of Wireless Sensor Networks", Hal. 931-934, Intelligent Computation Technology and Automation (ICICTA).

6. Munir, R., 2002, "Algoritma dan Pemrograman I", Penerbit Informatika Bandung.

7. Murugesan, S., 2008, "Harnessing Green IT: Principles and Practices", Vol. 10, No. 1, Hal 24- 33, IT Professional.

8. Murugesan, S., Gangadharan, G. R., 2012, "Harnessing IT: Priciples and Practices", John Wiley and Sons Ltd.

9. Restorick, T., 2007, "An Inefficient Truth", Global Action Plan Report.

10. Shih, E., Cho, S., Ickes, N., Min, R., Sinha, A., Wang, A., Chandrakasan A., 2001, "Physical layer driven protocol and algorithm design for energy-efficient wireless sensor networks", Hal. 272-287, MOBICOM 2001.

11. Turban, E., King D., Lee, J., Viehland, D., 2008, "Electronic Commerce A Managerial Perspective", Prentice-Hall.

12. New Scientist (2010), World's Communications Network due an Energy Diet, January, (2010), http://www.newscientist.com/article/ mg20527435.400-worlds-communicationsnetwork-due-an-energy-diet.html, diakses Maret 2013.

13. Scientific American (2010), "Can the World's Telecoms Slash Their Energy Consumption 1,000-Fold?", January, http://www.scientificamerican.com/article.cfm?id=green-touchlaunch, diakses Maret 2013.

14. Quantenna Communications, 2013, "Dramatic Improvement in Wi-Fi 802.11n Performance", http://www.quantenna.com/beamfor ming. html, diakses Maret 2013
15. http://www.pcmag.com/encyclopedia/ term/59493/insertion-sort, diakses Maret 2013.

16. http://www.pcmag.com/encyclopedia_ term $/ 0, \mathrm{t}=\& \mathrm{i}=55708,00$.asp, diakses Maret 2013.

17. NTT EAST, "Reducing GHG Emmisions through Automated Meter Reading and Centralized Monitoring System, http://www.ntt. co.jp/kankyo/e/protect/greenbyict/group. html, diakses Maret 2013.

\section{BIOGRAFI PENULIS :}

\section{Prio Handoko, M.T.I}

Program Studi Teknik Informatika Universitas Pembangunan Jaya Jl. Boulevard Bintaro Sektor VII Bintaro Jaya, Tangerang Selatan 15224. 